\title{
Professores de Matemática e Percepções Acerca do Uso de Materiais Institucionalizados Pelo Currículo do Estado de São Paulo
}

\author{
Oscar Massaru Fujita ${ }^{1}$ \\ Raquel Gomes de Oliveira ${ }^{2}$ \\ Maria Cecília Fonçatti ${ }^{3}$ \\ Erika Aparecida Navarro Rodrigues ${ }^{4}$
}

1 Doutorado em Educação pela Universidade de São Paulo (USP). Mestrado em Educação pela
Universidade Estadual Paulista Júlio de Mesquita Filho (Unesp). Especialização em Consultoria
Empresarial pela Fiaet. Estágio Profissional em Tecnologias pelo Distrito de Saitama-Ken,
Tóquio - Japão. Licenciatura em Matemática pela Unesp. Membro do Grupo de Pesquisa
Ensino e Aprendizagem, Matemática e Ciências Naturais (GPEA) como Objeto da Formação
de Professores - Unesp. Consultor Educacional em Projetos de Educação a Distância (EAD).
oscarfujita@ @outlook.com
2 Doutorado em Educação pela Faculdade de Educação da USP. Mestrado em Educação Matemática
pela Faculdade de Educação da Unicamp. Licenciada em Matemática pela FCT - Unesp. Professora
do Departamento de Educação e do Programa de Pós-Graduação em Educação da FCT - Unesp.
Membro do Grupo de Pesquisa Ensino e Aprendizagem, Matemática e Ciências Naturais (GPEA)
como Objeto da Formação de Professores - Unesp. senhoraraquel@ gmail.com
3 Doutoranda em Educação pela Universidade Estadual Paulista Júlio de Mesquita Filho (Unesp).
Mestrado em Matemática Aplicada e Computacional. Licenciada em Matemática pela Unesp.
Professora bolsista do Departamento de Matemática da FCT/Unesp. Membro do Grupo de Pesquisa
Ensino e Aprendizagem, Matemática e Ciências Naturais (GPEA) como Objeto da Formação de
Professores - Unesp. mcmaria18@ hotmail.com
4 Mestranda em Educação na FCT/Unesp. Graduada em Matemática pela Unesp de Presidente
Prudente. Graduada em Pedagogia pela Unesp/Univesp. Professora titular de cargo na Secretaria
do Estado de Educação de São Paulo, designada na função de coordenadora do Núcleo Pedagógico
de Matemática - Diretoria de Ensino de Presidente Prudente. Membro do Grupo de Pesquisa
Ensino e Aprendizagem, Matemática e Ciências Naturais (GPEA) como Objeto da Formação de
Professores - Unesp. erikaro3@ hotmail.com 


\title{
Resumo
}

Este texto analisa as percepções dos professores de Matemática quanto à utilização de materiais curriculares institucionalizados pela Secretaria de Educação do Estado de São Paulo (Seesp). 0 Caderno do Professor e o do Aluno compõem tais materiais, cujas finalidades e utilização motivaram questionamentos e reflexões a respeito de suas características, de suas necessidades e das condições de sua aplicabilidade. Indagar os professores sobre a contribuição desses materiais na prática docente significa a linha mestra deste trabalho. As ações de descrever e de analisar as respostas desse questionamento fazem parte de uma pesquisa qualitativa, descritivo-interpretativa. Seu percurso analisa o processo de formação de professores de Matemática e Ciências da Natureza para a instituição do currículo, bem como seus reflexos na prática docente. Os resultados revelam que os professores entendem parcialmente essa contribuição curricular para seu trabalho docente. A maioria deles não reconhece no currículo e em seus pressupostos questões referentes à gestão curricular, autonomia docente e flexibilidade para 0 desenvolvimento dos conteúdos. Como consequência, acatam o uso desse material ou negam sua utilização. Esses resultados reforçam a necessidade do desenvolvimento de saberes e competências desses pressupostos que deveria ocorrer desde a formação inicial do professor até na formação continuada, a partir de ações institucionalizadas da Seesp.

Palavras-chave: Currículo. Prática docente. Educação Matemática. Formação de professores.

\section{MATHEMATICS TEACHERS AND PERCEPTIONS ABOUT THE USE OF INSTITUTIONALIZED MATERIALS BY THE CURRICULUM OF SÃO PAULO STATE}

\begin{abstract}
This text analyzes the perceptions of Mathematics teachers regarding the use of curricular materials institutionalized by the São Paulo Secretary of Education (SPSE). The Teacher's Notebook and the Student's Notebook compose those materials, whose purposes and uses have motivated questions and reflections about their characteristics, needs and conditions of its applicability. The master line of this work is to inquire the teachers about the contribution of those materials to teaching practice. Describing and analyzing the answers to this questionnaire are part of a qualitative, descriptive-interpretive research. It's course analyzes the process of teacher training in Mathematics and Natural Sciences for an implementation of the curriculum, as well as its reflexes in teaching practice. The results show that teachers partially understand this curricular contribution to their teaching practice. Most of the teachers do not recognize in the curriculum and in their presuppositions issues related to curricular management, teaching autonomy and flexibility for content development. As a consequence, they either respect the use of this material or deny its use. These results reinforce the need to develop knowledge and competences of these assumptions that should occur since the initial teacher education as in their continued formation from institutionalized actions by SPSE.
\end{abstract}

Keywords: Curriculum. Teaching practice. Mathematics Education. Teacher training.

Recebido em: 30/6/2017

Aceito em: 7/9/2017 
O currículo do Estado de São Paulo, estabelecido em 2008, pela Secretaria Estadual de Educação (Seesp), abrange a rede pública de Ensino Fundamental e Médio paulista em toda sua extensão. Oferece material curricular padronizado, na forma de Caderno do Professor e do Aluno, englobando diferentes áreas do conhecimento. Uma equipe de especialistas elaborou os cadernos, fato que suscitou questionamentos e discussões no que tange as suas características, seja quanto à forma, seja quanto ao conteúdo. Por conseguinte, a utilização desses cadernos pelos professores de Educação Básica desperta o interesse dos pesquisadores e mobiliza suas reflexões.

Nesse contexto de pesquisa e reflexão, o Grupo de Pesquisa GPEA Ensino e Aprendizagem como Objeto da Formação de Professores - centra suas motivações em questões sobre o processo de ensino e aprendizagem, entendido como uma dimensão nuclear da competência profissional docente. Ele pretende, portanto, analisar as implicações na formação de professores de cursos de Licenciatura em Matemática e em Ciências Naturais e nas suas atuações no âmbito da Educação Básica, promovendo estudos sobre aquisição/construção de conceitos ligados aos diferentes aspectos do saber escolar.

Tais reflexões deram origem a uma pesquisa iniciada em 2014, cujo objetivo visou à análise do processo de formação de professores de Matemática e de Ciências da Natureza proposto e desenvolvido para a instituição do currículo da Secretaria de Educação do Estado de São Paulo (Seesp). Igualmente, também focalizou seus reflexos na prática docente, tomando como referência a realidade do município de Presidente Prudente - SP, a partir da descrição que os professores fizeram da sua prática e do processo de formação, no contexto da referida prática curricular.

Entre as etapas da pesquisa, esta se refere às percepções dos professores quanto à proposta curricular da Seesp. Dela, levantam-se os resultados. As análises de conteúdo das respostas respondem pela tabulação de dados, seguida da definição de categorias e subcategorias, a partir da articulação dos diferentes dados coletados com base no referencial teórico e em pesquisas relativas ao tema. 


\section{Currículo: um contexto para a pesquisa...}

A organização curricular não deve ser vista como algo determinado, fechado, acabado (RIBEIRO, 2004). É fundamental que os documentos que constituem o currículo sejam retomados de forma permanente por meio de reflexão, ação, avaliação e uma nova ação. Isso deve ocorrer por mediante um processo democrático que envolve decisões e intenções.

O currículo é entendido como um instrumento orientador da ação educativa em sua totalidade. A sua elaboração, por ser um trabalho partilhado, envolve crenças, princípios, valores, convicções, conhecimentos sobre a comunidade acadêmica, sobre o contexto científico e social e constitui um comprometimento político e pedagógico coletivo (RIBEIRO, 2004, p. 13).

Ferreira (2000, p. 15) confirma essa opinião. Ele defende o conceito de currículo como uma construção social, a qual não pode, dessa forma, ser considerada neutra e atemporal. Tal compreensão "exclui a proposição de modelos prontos" para que os atores apenas o executem.

Giroux e Shannon (1997 apud PACHECO, 2006, p.11) complementam o entendimento, afirmando que o currículo tem como missão

[...] intervir, questionar, problematizar no sentido de uma prática performativa, isto é, não na perspectiva da eficiência dos resultados, dos procedimentos algorítmicos, mas numa abordagem que nos revele um espaço narrativo que evidencie o contexto e os aspectos específicos, ao mesmo tempo em que reconheça os modos pelos quais tais espaços estão impregnados por questões de poder.

Para Goodson (2007, p. 243), essa impregnação de poder leva-nos a praticar o currículo de forma equivocada, como uma forma de "dirigir e controlar o credenciamento dos professores e sua potencial liberdade nas salas de aula", estando, portanto, associada aos conceitos de prescrição e de poder. Nessa perspectiva, ele acabou se tornando um "objeto de reprodução das relações de poder já existentes na sociedade”. 
O significado de currículo como instrumento de reprodução de poder, descaracterizado de considerações contextuais para sua realização, que acontece em cada sala de aula, a partir de cada professor e de cada aluno, oportuniza entender tanto a participação minimizada e, muitas vezes, nula, de professores, no processo de construção de propostas curriculares, bem como sua consequência.

Nessa direção, nos Estados Unidos, as reformas curriculares realizadas na primeira metade do século passado fracassaram.

Na concepção de Remillard (2005), entre as causas desse fracasso constam a não relevância, pelos especialistas, do papel do professor na sala de aula e da relação entre esse e o currículo. Também se sobressai a incapacidade dos especialistas para "antecipar a capacidade dos professores para interpretar de forma incorreta, subverter e até mesmo ignorar um currículo não familiar" (p. 212).

No que se refere ao processo de constituição de materiais curriculares, tomando-se a realidade brasileira, para Pires e Curi (2013b) esse processo tem carecido de acompanhamento efetivo e sistemático.

Dessa forma, torna-se relevante o entendimento sobre o que acontece com professores e alunos em relação ao material curricular proposto pela Seesp.

Conhecer e analisar esse material permitirá entender, entre outros fatos, como as escolhas dos professores têm orientado suas atividades em sala de aula e quais reflexos suas escolhas podem causar na prática docente (REMILLARD; HERBEL-EISENMANN; LLOYD, 2009; PIRES; CURI, 2013b).

Para entender as diferentes formas que professores se relacionam com os materiais curriculares requer uma análise de como as características dos materiais interferem nas ações dos professores, ou seja, como os professores se adaptam, adotam ou improvisam com essas matérias em sala de aula (BROWN, 2009 apud PIRES; CURI, 2013a, p. 47).

O entendimento das escolhas dos professores e o reconhecimento sobre como elas implicam nas práticas docentes também é relevante para Sacristán (2008) e Rico (2013). Os teóricos consideram que são os professores os principais personagens do processo de transformação dos ideais curriculares, os quais 
se expressam de forma indireta e por meio de seus planos de aula, de sua ação docente, de estratégias didáticas e suas atividades e também por meio de suas recomendações pedagógicas.

Materiais curriculares espelham pressupostos e graus de compreensão sobre currículo e seus diversos significados (REMILLARD, 2005; PIRES; CURI, 2013b; SACRISTÁN, 2008; RICO, 2013).

Os significados revelam-se distintos em curriculistas ao descreverem categorias como: currículo formal, que propõe, por especialistas, objetivos e atividades escolares, currículo esperado ou intencionado, que se refere aos objetivos dos professores e currículo realizado/vivenciado nas salas de aula (REMILLARD, 2005). Geralmente as concepções que delineiam o conceito de currículo sinalizam conflitos conceituais e problemas principalmente voltados à prática docente.

Pires (2009, p. 170) reforça que as reformas curriculares não têm considerado alguns aspectos das experiências anteriores. Em consequência, elas têm se perdido no tempo e em seus desdobramentos. De forma geral, constatam-se poucas ações formativas envolvendo um processo contínuo, visão ampliada de planejamento e de um verdadeiro projeto educacional. Semelhantes ações encaminham-nos a conviver apenas com currículos prescritivos que constam nos documentos oficiais

Goodson (2007, p. 242) por sua vez, salienta que "precisamos mudar de um currículo prescritivo para outro como identidade narrativa”. Somente assim avançaremos para um currículo que leve em conta os objetivos e os significados que os indivíduos têm para as suas vidas. Embora pareça levemente significativa, nesse ponto de vista, altera-se decisivamente a forma como as ações ocorrem nas escolas e no interior das salas de aula.

Se analisarmos o Brasil dos anos 80, período de abertura democrática, perceberemos que as propostas curriculares no Estado de São Paulo foram elaboradas com a participação dos professores, entretanto tal compartilhamento não garantiu efetivamente que os princípios da proposta fossem materializados em atividades de sala de aula, devido às crenças já cristalizadas por professores, que geravam resistência à aplicação da proposta (PIRES, 2009). 
As preocupações dos autores anteriormente citados sobre as características que marcam o currículo prescritivo e suas consequências, permitem entender, em parte, o que é suposto como resistência das escolas no processo de instituição curricular. De um lado, temos um currículo prescrito; de outro, professores que vivenciam, no seu cotidiano, aspectos relacionados às demandas dos alunos reais, com interesses específicos, heterogêneos e com condições de trabalho que, na maioria das vezes, não priorizam os processos de reflexão.

Conhecer, portanto, as concepções e as relações de professores de Matemática quanto aos materiais curriculares da Seesp vai ao encontro da necessidade de se produzir conhecimento. Mais ainda, que ele seja generalizável a outros professores, a outros materiais e contextos, trazendo em seu bojo, igualmente, a capacidade de constituir referência teórico-prática para educadores, gestores e curriculistas (REMILLARD; HERBEL-EISENMANN; LLOYD, 2009).

\section{Ações Metodológicas da Pesquisa}

A fim de investigar percepções dos professores sobre o material curricular proposto pelo Estado de São Paulo, desenvolveu-se uma pesquisa qualitativa que descreveu e analisou dados obtidos de 80 professores de Matemática (64,8\% do total de 125 professores, que atuavam em 24 escolas do município de Presidente Prudente (SP)). Os pesquisadores coletaram os dados a partir de um questionário aplicado aos docentes com o objetivo de caracterizar o grupo pesquisado (formação, tempo de experiência e situação funcional). O material de pesquisa também questionou os profissionais a respeito de sua opção em relação ao uso do material curricular, bem como a contribuição deste para sua prática pedagógica. Duas etapas ocuparam o desenvolvimento da respectiva pesquisa.

Primeiramente, realizou-se uma análise documental, a partir dos documentos, materiais elaborados e divulgados pela Seesp, especificamente para o ensino de Matemática. Igualmente, contemplaram-se aqueles utilizados para a formação dos professores e no processo de instituição do currículo, de modo a investigar os fundamentos didático-epistemológicos e político-pedagógicos da proposta curricular. 
Esse tipo de análise procura identificar informações nos documentos pesquisados, enfatizando questões de seu interesse.

Significa, por conseguinte, uma importante fonte de dados, da qual se extraem evidências que fundamentam as afirmações e/ou negações do processo de investigação (LÜDKE; ANDRÉ, 1986).

$\mathrm{Na}$ sequência foram aplicados questionários a todos os professores de Matemática das 24 escolas de Ensino Fundamental e Médio do município de Presidente Prudente (SP).

Para o primeiro levantamento de dados utilizou-se um questionário com o objetivo de identificar os professores. Em um segundo momento investigamos suas opções em relação ao uso do material (Caderno do Professor e do Aluno) para precisar a descrição que fazem de sua prática docente, a partir dessa instituição curricular. A opção por esse instrumento possibilita levantamento de dados quando se quer atingir uma população mais numerosa (CERVO, 1996).

Duas partes compunham o questionário que apresentava as questões investigativas. Questões relativas à formação e atuação do professor ocupavam a primeira e outras que diziam respeito ao emprego do material, ao uso feito pelo professor e a suas percepções acerca disso preenchiam a segunda. Nessa parte as questões foram divididas novamente entre as que se referiam à formação docente para o uso do material e aquelas exclusivamente sobre o material no trabalho docente.

Sobre esse conteúdo, avoluma-se a questão que será por nós analisada no presente texto. Quer dizer, os professores foram questionados sobre a contribuição do uso dos materiais de apoio do currículo oficial do Estado de São Paulo para a melhoria de seu trabalho e para a aprendizagem de seus alunos. Assim, este texto apresenta resultados e análises dessa questão, cujas opções de respostas eram "Sim", "Não", "Em parte” e "Em branco".

Um total de 80 professores responderam a essa questão. A partir da leitura de todas as justificativas que compareceram em cada opção de resposta, foi possível a elaboração de um conjunto de categorias. Elas foram organizadas sistematicamente em forma de tabelas, que nos auxiliaram na análise dos dados. 


\section{Resultados da Pesquisa}

O questionário aplicado aos professores de Matemática perguntou-lhes se o uso dos materiais de apoio do currículo oficial do Estado de São Paulo tem contribuído para seu trabalho docente. Nas respostas, eles deveriam escolher entre uma das alternativas: Sim, Não e Em parte, as quais também deveriam justificar. Categorizamos como Em branco, aqueles que não assinalaram qualquer uma das alternativas.

Tabela 1 - Frequência de respostas sobre a contribuição dos materiais de apoio para o trabalho do professor

\begin{tabular}{lcc}
\multicolumn{1}{c|}{ Respostas } & Frequência & $\%$ \\
\hline Em parte & 43 & 53,7 \\
Sim & 25 & 31,3 \\
Não & 9 & 11,2 \\
Em branco & 3 & 3,8 \\
\hline TOTAL & $\mathrm{N}=80$ & 100,0 \\
\hline
\end{tabular}

Fonte: Dados coletados pelos autores.

Foi possível a construção de um conjunto de categorias (Tabela 2), no qual as justificativas estão relacionadas ao aluno, ao material, ao professor e à Seesp. As respostas dos participantes puderam ser classificadas em uma ou mais categorias. Dessa forma, nossa análise levará em conta o total de repostas em cada categoria e não o número de participantes.

Tabela 2 - Frequência de respostas quanto à contribuição dos materiais de apoio

\begin{tabular}{l|c|c|c|c|c|c}
\hline \multirow{2}{*}{ Categorias } & \multicolumn{2}{c|}{ Sim } & \multicolumn{2}{c|}{ Não } & \multicolumn{2}{c}{ Em parte } \\
\cline { 2 - 7 } & Frequência & $\%$ & Frequência & $\%$ & Frequência & $\%$ \\
\hline A - Em relação ao aluno & 4 & 11,4 & 3 & 25,0 & 1 & 2,1 \\
B - Em relação ao material & 12 & 34,3 & 8 & 66,7 & 28 & 59,6 \\
C - Em relação ao professor & 13 & 37,1 & 0 & 0,0 & 4 & 8,5 \\
$\begin{array}{l}\text { D - Em relação à política } \\
\text { da Secr. }\end{array}$ & 1 & 2,9 & 0 & 0,0 & 0 & 0,0 \\
Respostas aleatórias & 3 & 8,6 & 0 & 0,0 & 0 & 0,0 \\
Em branco & 2 & 5,7 & 1 & 8,3 & 14 & 29,8 \\
\hline TOTAL & $\mathrm{N}=35$ & 100,0 & $\mathrm{~N}=12$ & 100,0 & $\mathrm{~N}=47$ & 100,0 \\
\hline
\end{tabular}

Fonte: Dados coletados pelos autores. 


\section{Sobre as Respostas para a Opção Sim}

Conforme a Tabela 1 , dos 80 (oitenta) professores que responderam à questão, 25 (vinte e cinco) deles escolheram a alternativa Sim, visto que entendem que o material curricular da Seesp contribui para seu trabalho docente. Nessas afirmações, ocorreram 35 (trinta e cinco) justificativas (Tabela 2): 13 (treze) delas relacionadas ao professor $(37,1 \%), 12$ (doze) ao material $(34,3 \%)$, 4 ao aluno $(11,4 \%)$, uma tão somente à Seesp $(2,9 \%)$ e duas $(5,7 \%)$ em branco.

No contexto das justificativas, 13 (treze) delas $(37,1 \%)$ explicitam a contribuição do material para o trabalho docente relacionada ao professor. Essa ajuda está ligada ao fato, segundo os respondentes, de que o material curricular facilita o planejamento das aulas $(34,3 \%)$ e colabora com o saber docente $(2,9 \%)$ "estimulando o aperfeiçoamento do professor". Ao apontar que o material curricular facilita, em relação ao professor, o planejamento das aulas, os participantes destacaram que "o tempo para preparar a aula torna-se menor", que "é um guia do trabalho do professor" e que "ajuda na preparação do conteúdo".

As justificativas que nomeiam a contribuição ao trabalho docente ao próprio material curricular referem-se à forma de apresentação e à organização $(28,5 \%)$, seguida da operacionalização do processo didático $(5,7 \%)$. Nas respostas, os professores consideraram que a organização em situações de aprendizagem, com uma determinada sequência de conteúdo, as atividades práticas para os alunos e com contextualização, contribuem para seu trabalho docente.

Prof85 - "Porque esse material já vem inserido na situação de aprendizagem ficando mais prática sua aplicação".

Prof8 - "São materiais que ajudam na apresentação dos conteúdos aos alunos e selecionam os mesmos ao cotidiano desses alunos".

Quanto aos aspectos operacionais do processo didático, as justificativas referem-se às contribuições das orientações do Caderno do Professor e o fato de o material ser apostilado e padronizado pela Seesp. 
Prof51 - "É preciso estar atenta para poder explicar os conteúdos abordados no currículo. Há ganho de tempo, pois não é preciso ficar passando na lousa. Há atividades práticas".

Prof70 - "Contribui devido a algumas explicações que o caderno do professor mostra junto ao conteúdo tratado no currículo".

Em relação ao aluno, as justificativas da contribuição do material para o trabalho docente foram relacionadas a aspectos cognitivos $(11,4 \%)$. Elas referem-se ao desenvolvimento de competências e habilidades $(8,6 \%)$ e à facilidade de compreensão do conteúdo $(2,9 \%)$.

No campo significativo da Secretaria de Educação do Estado de São Paulo, a justificativa dos professores sobre a contribuição do material para seu trabalho docente está relacionada à política governamental (2,9\%), atribuindo a obrigatoriedade do uso do material.

\section{Sobre as Respostas para a Opção Não}

Conforme a Tabela 1, para a opção de resposta Não, 9 dos 80 participantes responderam que o material não contribui para sua prática docente. As respostas traduziram 11(onze) justificativas (Tabela 2), 8 (oito) delas relacionadas ao material $(66,7 \%)$ e 3 relacionadas ao aluno $(25,0 \%)$.

Os professores de Matemática que expressam que o material não contribui para sua prática docente justificam sua negação indicando forma da apresentação e a organização do material $(41,7 \%)$, seguido de conteúdo insuficiente $(25,0 \%)$. Acrescentam ainda que a abordagem do material é inadequada, descrevendo a necessidade de sua complementação e o conteúdo incompleto.

As três justificativas da não contribuição do material para a prática docente, quando relacionadas ao aluno $(25,0 \%)$, evidenciaram aspectos cognitivos como a discrepância entre o conteúdo apresentado no material da Seesp e o nível cognitivo do aluno e sua dificuldade para a compreensão do conteúdo.

Prof24 - "Me sinto perdida quanto à utilização dos materiais, pois não consigo o retorno esperado, devido à defasagem dos alunos". 
Prof115 - "Tudo que for trabalhado, tem que ser explicado separadamente. Na apostila o aluno não consegue caminhar apenas com a explicação desse material".

Ao todo, 201 (duzentos e um) aspectos relacionados ao material da Seesp foram mencionados pelos 80 professores como dificultadores de suas práticas docentes. Esses aspectos expressaram dificuldades que também foram relacionadas ao aluno $(13,4 \%)$, ao próprio material $(74,6 \%)$, ao professor $(5,5 \%)$, à escola $(1,0 \%)$ e à política da Seesp $(5,5 \%)$.

Assim, 150 (cento e cinquenta) aspectos considerados pelos professores como dificultadores de suas práticas docentes estavam relacionados ao material. Quanto à estrutura e organização do material da Seesp, 30 (trinta) desses aspectos $(20,0 \%)$ referiam-se ao conteúdo: abordagem, conteúdos não tratados corretamente, falta de informação, falta de conteúdo, teoria, pouco conteúdo, fraco, superficial, sem conteúdo, sem introdução, sem exemplos, muitas vezes incompleto. Sobre as características das atividades que se encontram no material, 24 (vinte e quatro) aspectos $(16,0 \%)$ identificaram-se com apresentação do conteúdo, apresentação difícil para os alunos, material pouco atrativo para os estudantes, poucas ilustrações.

Ainda sobre as características das atividades, 23 (vinte e três) aspectos $(15,3 \%)$ relacionavam-se a exercícios, atividades (quantidade), poucos exercícios, atividades, situações de aprendizagem. Por fim, igualmente tidos como características das atividades do material, 17 (dezessete) aspectos (11,3\%) se identificaram com: faltam conteúdos prévios dos alunos, alunos devem estar no mesmo nível, dificuldades, incompatível com a realidade dos alunos/das escolas.

Tanto na citação de aspectos dificultadores para seus trabalhos docentes quanto nas respostas negativas sobre a contribuição do material da Seesp, os resultados evidenciam que, para esses professores, a não contribuição do material e aspectos dificultadores para a prática docente têm origem no próprio material da Seesp, mais precisamente no tocante a sua forma e ao seu conteúdo. 
Vale ressaltar que é importante a complementação do conteúdo e que ela está prevista no próprio material, no entanto esse fato não foi considerado pelos docentes pesquisados como dado positivo, uma vez que sua posição é categórica: o material não contribui para a prática docente.

\section{Sobre as Respostas para a Opção Em parte}

De acordo com a Tabela 1 , a maioria dos professores $(53,7 \%)$ considerou que o material contribui em parte para o seu trabalho. Dos 43 (quarenta e três) respondentes, que optaram por essa alternativa, 14 (catorze) não justificaram sua adesão. Vinte e nove professores comunicaram 33 (trinta e três) justificativas - porque um mesmo profissional pode expressar mais de uma delas - as quais foram categorizadas em relação ao aluno, ao professor e ao material, e a última destacou-se perante as outras. Entre elas distinguiram-se aspectos negativos e positivos para justificar o porquê dessa contribuição parcial, sendo eles predominantemente negativos.

Em relação ao aluno, de acordo com a Tabela 2, tivemos apenas uma justificativa negativa, isto é, um professor $(2,1 \%)$ justificou que a contribuição só não é maior devido à falta de interesse dos alunos e à progressão continuada, dado que, para ele o material "não corresponde à realidade" e "com a progressão continuada os alunos são estimulados a não se interessar pelos conteúdos e pela aprendizagem" - Prof33.

No momento de avaliar o material emergiram aspectos negativos e positivos. As críticas tiveram como foco gerador o conteúdo e a forma com que ele é apresentado. Vinte e dois professores $(46,8 \%)$ observaram que há a necessidade de complementação do conteúdo, uma vez que "os materiais não são suficientes para garantir a aprendizagem dos alunos", "são fora da realidade", "alguns (conteúdos) não são aplicáveis ao nível cognitivo dos alunos" - Prof27. Eles acrescentam que, para ajudar em seu trabalho, o material "precisa ser completo, sem precisar usar o livro didático". Apenas um professor $(2,1 \%)$ justificou que o "material traz bons exercícios e isso contribui para seu trabalho" - Prof86. 
A forma de apresentação e organização do material também apareceu como aspecto positivo e negativo: quatro professores $(8,5 \%)$ criticaram o fato de os conteúdos aparecerem no material de forma diferente de como eles estão acostumados: "tivemos uma outra formação", e um professor $(2,1 \%)$ disse que a "contribuição para seu trabalho vem do fato de que o material contém exercícios que reforçam o aprendizado e complementam o conteúdo, podendo ser resolvidos em casa”.

No que diz respeito à avaliação do professor, as justificativas foram apenas positivas: um professor $(2,1 \%)$ destacou que para ele a "contribuição do material depende de como ele é trabalhado em sala de aula", ou seja, depende de o professor fazer com que tal material seja bom para o aprendizado de seus alunos. A autonomia possibilitada pelo material foi apontada por um entrevistado $(2,1 \%)$. Dois professores $(4,2 \%)$ mencionaram a contribuição para a prática docente, tendo em vista que, segundo eles, o material complementa seu trabalho.

Os relatos recolhidos esclarecem que, para a maioria dos professores, é possível trabalhar com o material, desde que sejam realizadas algumas modificações, por exemplo: a introdução de conteúdo suplementar e a mudança na forma como ele será apresentado. Isso explicita o mesmo problema encontrado nas justificativas das respostas Não, ou seja, ocorre a limitação do conhecimento por parte dos professores sobre a necessidade de complementação de conteúdo, embora essas recomendações já estejam previstas no próprio material.

\section{Análise dos Resultados}

Quando analisamos o conteúdo das respostas acompanhadas das respectivas justificativas expressas pelos professores, cujo referente é a contribuição dos materiais curriculares da Seesp para seu trabalho docente, somos encaminhados a buscar o contexto das apresentações desses currículos, tendo como base o olhar e a ênfase dados pela própria Seesp. 
A Seesp, em 2008, levou em consideração os resultados do Sistema de Avaliação de Rendimento do Estado de São Paulo (Saresp) obtidos em 2005 e a necessidade de elaboração, ampliação e consolidação das habilidades em todas as disciplinas escolares pelos alunos.

Em consequência, apresentou-se uma Proposta Curricular a ser estabelecida a partir de um projeto denominado "São Paulo Faz Escola," cujas ações didático-pedagógicas estavam inspiradas em um movimento de ação-reflexão-ação com "[...] práticas em sala de aula que propõem a consolidação das habilidades de leitura e produção de texto, e matemáticas identificadas pelo Saresp" (SÃO PAULO, 2008a, p. 4).

Assim sendo, supunha-se que "[...] o material pode servir de referências para novas práticas e, fundamentalmente, para orientar o planejamento do ano letivo, com base em uma reflexão sobre os resultados obtidos durante a aplicação das práticas indicadas" (SÃO PAULO, 2008a, p. 5). O Jornal do Aluno apresentava "[...] atividades (situações-problema com a temática da disciplina e o desenvolvimento de habilidades do Saresp)" (SÃO PAULO, 2008a, p. 8). As Revistas destinadas aos professores eram apresentadas como textos que detalhavam "[...] as possibilidades de aplicação e de avaliação das atividades propostas para o aluno no jornal” (SÃO PAULO, 2008a, p. 11).

O projeto "São Paulo Faz Escola" representou a base da Proposta Curricular do Estado de São Paulo apresentada pela Seesp em 2008, tendo como princípios curriculares: "a escola que aprende, o currículo como espaço de cultura, as competências como eixo de aprendizagem, a prioridade da competência de leitura e de escrita, a articulação das competências para aprender e a contextualização no mundo do trabalho" (SÃO PAULO, 2008b, p. 11).

Referendada pelos pressupostos desses princípios, a Proposta Curricular esclarecia o que era esperado do aluno em termos de desenvolvimento, ampliação e consolidação de competências associadas aos eixos que orientavam as práticas

5 Projeto São Paulo Faz Escola - era composto pelo jornal do aluno ( $5^{\text {a }}$ série do Ensino Fundamental ao $3^{\circ}$ ano do Ensino Médio) e pela revista do professor (5 revistas para o Ensino Fundamental e 5 revistas para o Ensino Médio) para as áreas de conhecimento do currículo escolar (SÃO PAULO, 2008a). 
educativas na sala de aula: eixo expressão/comunicação; eixo argumentação/ decisão e eixo contextualização/abstração. Nos esclarecimentos curriculares sobre o que ensinar (conteúdos fundamentais) e sobre como ensinar (ideias fundamentais), a relação professor - material curricular deveria acontecer a partir do entendimento docente a respeito das características de abertura e de flexibilidade curriculares em relação à profundidade conceitual dos temas a serem ensinados pelos professores e, nesse sentido, administrando a gestão do tempo.

A escolha da escala correta certamente está relacionada à maturidade e à competência didática do professor em identificar as possibilidades cognitivas do grupo, bem como o grau de interesse que o tema desperta nos alunos (SÃO PAULO, 2008b, p. 48).

A Seesp defende em diversos momentos a não imposição da Proposta Curricular aos professores:

A escolha de diferentes escalas de aprofundamento para diferentes assuntos é natural e esperada. Cabe ao professor, em sua escola, respeitando suas circunstâncias e seus projetos, privilegiar mais ou menos cada tema, determinando seus centros de interesse e detendo-se mais em alguns deles, sem eliminar os demais. Tal opção sempre esteve presente como possibilidade na ação do professor, uma vez que propostas curriculares nunca poderiam ser impostas aos docentes (SÃO PAULO, 2008b, p. 48).

A Proposta Curricular alude às características da relação professor-material curricular encontradas, no Currículo do Estado de São Paulo, que, a partir de 2010, foi a denominação dada à Proposta Curricular de 2008. Nesse currículo são mantidos formas e conteúdos da Proposta Curricular (SÃO PAULO, 2008b) com inserções de exemplos de inicialização e aprofundamento de conteúdo, evidenciando-se como competência para ensinar, a capacidade de o professor fazer escolhas. Especificamente sobre a natureza da relação professor - material curricular, esta pode ser depreendida novamente da ideia do professor como gestor dos temas curriculares em questões como aprofundamento conceitual, metodologias, tempo de aula e outras como: 
Somente o professor, em sua escola, respeitando suas circunstâncias e seus projetos, pode ter o discernimento para privilegiar mais um tema do que outro, determinando seus centros de interesse e detendo-se mais em alguns deles, sem eliminar os demais. Tal opção sempre esteve presente como possibilidade na ação do professor; os currículos nunca poderão ir além de uma orientação geral fundamental no que se refere aos princípios e aos valores envolvidos, mas sempre dependentes da mediação do professor, em suas circunstancias específicas (SÃO PAULO, 2011, p. 50).

Nesse sentido, nos esclarecimentos da Seesp sobre pressupostos curriculares, é possível identificar o papel do professor, ao menos em oportunidades, como "[...] um mediador decisivo entre o currículo estabelecido e os alunos, um agente ativo no desenvolvimento curricular, um modelador dos conteúdos [...], condicionando, com isso, toda a gama de aprendizagens dos alunos" (SACRISTÁN, 2008, p. 166).

Papéis previstos e possíveis aos professores, contudo, tanto para um currículo em andamento quanto para a introdução de um currículo novo, podem variar, segundo o mesmo autor, “[...] desde o papel passivo de mero executor até o de profissional crítico que utiliza o conhecimento e sua autonomia para propor soluções originais frente a cada situação educativa" (SACRISTÁN, 2008, p. 178).

Ainda sobre o papel do professor na relação professor - material curricular, Tanner e Tanner (1980 apud SACRISTÁN, 2008) apresentam três níveis de possibilidade que caracterizam esse papel:

- Nível 1 (imitação-manutenção), o professor segue cumprindo tarefas, utilizando sem questionar os materiais didáticos. Procedimentos de introdução curricular considerados de cima para baixo destinam esse papel ao professor vinculado ao conceito de servidor público que age em um campo técnico-pedagógico.

- $\quad$ Nível 2 (mediação), os professores adaptam, modificam os materiais curriculares em virtude dos contextos reais nos quais ensinam: "Ele conhece os recursos do meio, da escola, as possibilidades dos seus 
alunos, etc., com o que pode realizar uma prática mais aperfeiçoada, interpretando e adaptando[...]" (TANNER; TANNER, 1980 apud SACRISTÁN, 2008, p. 179).

- Nível 3 (criação-geração), os professores agem em decorrência de diagnósticos, adaptações, pesquisas, reconhecimento de problemas, levantamento de hipóteses, trabalhando conjuntamente com outros professores, avaliando e regulando suas práticas docentes.

No campo de papéis diversificados atribuídos aos professores, quando eles desenvolvem um currículo, as questões que podem ser levantadas, cujas respostas podem fundamentar as justificativas para as respostas dos professores desta pesquisa, são: O que determina esses papéis e igualmente qual a motivação para o trânsito entre um papel e outro?

Junto ao protagonismo curricular do professor, baseado em sua identidade profissional e seus conhecimentos, entende-se que práticas e inovações curriculares são avaliadas pelo professor em termos de sua aplicabilidade.

[...] a falta de convicção acerca da possibilidade de realização de determinadas tarefas na aula ou a reduzida expectativa sobre os resultados que antecipa conseguir junto dos alunos, fazem com que o professor opte por não experimentar determinadas tarefas, metodologias, etc., que lhe são propostas (BROWN; CINTYRE, 1993 apud CANAVARRO; PONTE, 2005, p. 72).

Tal como a aplicabilidade das inovações curriculares, os saberes, as experiências docentes e os valores do professor também podem ser considerados como fatores motivadores para o papel desempenhado na relação professor material curricular. "As práticas curriculares do professor vivem muito daquilo que ele mais valoriza, do que efectivamente considera dever fazer, das informações a que tem acesso e do conhecimento prático que detém" (CANAVARRO; PONTE, 2005, p. 73).

Levando em consideração os fatos/dados apresentados na pesquisa que realizamos com os 80 professores de Matemática, as justificativas das respostas positivas de 25 (vinte e cinco) deles quanto à contribuição dos materiais curriculares da Seesp ao trabalho docente, referem-se em sua maioria ao professor e ao 
próprio material curricular. Essas justificativas se complementam no sentido de revelarem que houve, por parte dos enunciadores, o entendimento de seu papel na relação docente - material curricular que se identifica com as características do professor mediador entre pressupostos curriculares e currículo praticado, no sentido defendido por Sacristán (2008).

As ideias de ações docentes associadas ao planejamento, ao preparo das aulas, à gestão de tempo para essa atividade e ao seu desenvolvimento corroboram esta afirmação, do mesmo modo que aquelas que atribuem à forma e organização dos materiais curriculares o papel de organizadores da prática docente, ou seja, do que será desenvolvido em aula pelo professor.

As justificativas que se referem aos aspectos cognitivos dos alunos $(12,1 \%)$, no sentido do desenvolvimento de competências e facilidade para a compreensão dos conteúdos aliam-se ao conjunto de elementos que justificam o investimento do professor em uma inovação curricular no sentido de ele ter a consciência do objetivo de desenvolvimento de um currículo. Ainda contribui para a identificação do entendimento de mediador na relação professor - material curricular e não de um simples aplicador de prescrições curriculares, o fato de apenas 3,0\% das justificativas estarem associadas à política governamental da Seesp.

Em conformidade com as respostas negativas dadas pelos 9 professores, suas respectivas justificativas relacionam-se em sua maioria com a forma de apresentação e organização dos materiais curriculares, seguida de apontamentos quanto à insuficiência dos conteúdos implicando a necessidade de complementá-los, além de apontamentos de discrepância entre níveis cognitivos dos alunos e conteúdos apresentados.

Aliados a essas justificativas como aspectos específicos apontados no material em relação a dificuldades de entendimento por parte dos alunos e características das atividades permitem inferir que esses professores não realizaram uma interpretação adequada dos pressupostos curriculares condizente com aqueles apresentados pela Seesp, o que certamente levou ao não desenvolvimento 
de seu real papel na relação professor - material curricular, tendo em vista as características de flexibilidade do currículo, esclarecido e defendido pela Seesp em termos de temas curriculares e gestão do tempo.

Afirmações dos professores sobre aspectos dificultadores dos materiais curriculares (falta informação e conteúdo, sem exemplos, apresentação difícil e pouco atrativa para os alunos, incluindo as de professores que reconhecem a contribuição dos materiais curriculares da Seesp em suas práticas docentes, levam a pensar no trânsito entre o papel de seguidor e aplicador de prescrições curriculares, de mediador e o papel de criador de materiais curriculares a partir de motivações como apontadas por Canavarro e Ponte (2005), tais como: falta de tempo, concepções sobre o currículo de Matemática, características e atitudes dos alunos, entre outros.

Diferentemente das opções de resposta Sim e Não, mutuamente excludentes e, portanto, implicando que as suas respectivas justificativas já sinalizassem possibilidades de inferências sobre o papel assumido pelo professor na relação professor - material curricular, no sentido de Tanner e Tanner (1980 apud SACRISTÁN, 2008), as justificativas para a opção de resposta Em Parte levam a refletir tanto sobre o papel assumido pelo professor nessa relação quanto sobre a possibilidade de trânsito dos professores entre um papel e outro.

Mesmo não negando a contribuição dos materiais curriculares para seus trabalhos docentes, $66,7 \%$ das 33 justificativas, oriundas de 43 respostas, apontam para a necessidade de complementação do material curricular. Outras justificativas também com aspectos negativos estavam associadas à forma de apresentação e conteúdo do material. Observa-se então que, para a maioria dos professores, é possível trabalhar com o material desde que sejam feitas algumas modificações, como a introdução de mais conteúdo e a mudança na forma como esse conteúdo é apresentado. Isso explicita o mesmo problema encontrado nas justificativas das respostas Não, ou seja, existe a falta de conhecimento dos professores sobre a necessidade de complementação de conteúdo já estar prevista no próprio material. 
Todas as justificativas que puderam ser consideradas com cunho negativo por parte dos professores que entendem como parcial a contribuição do material curricular da Seesp ao trabalho docente levam a buscar compreender as interpretações desses professores acerca do currículo e suas consequências, bem como seus entendimentos do papel a ser exercido por um professor na relação professor - material curricular.

Igualmente as justificativas de cunho positivo permitem afirmar o entendimento dos professores quanto aos pressupostos curriculares da Seesp, que estruturam os materiais curriculares, como também o entendimento de seu papel na relação professor - material curricular a partir desses pressupostos.

Assumir como parcial a contribuição do material curricular para seu trabalho docente, mas atribuindo aos materiais condições e necessidades e, portanto, limitações, que não existiriam, a partir do entendimento das orientações e pressupostos curriculares da SEESP quanto ao currículo de Matemática, pode ser explicado a partir dos esclarecimentos de Roldão (1999) sobre competências e formação docente para a gestão curricular, considerando diferentes campos e níveis da decisão curricular.

Nessa perspectiva, "Decidir o quê? - Como - Com quem?" (ROLDÃO, 1999 , p. 55) justificam a necessidade de formação docente inicial e contínua para a gestão curricular, tendo em vista o desenvolvimento e a ampliação de saberes docentes sem os quais o entendimento da filosofia de um currículo, de seus pressupostos e demais condicionantes da relação professor - material curricular-limitam possibilidades curriculares e pouco contribuem para o alcance de objetivos curriculares, sejam estes dos sistemas educativos ou de cada escola. Apesar, no entanto, de ser considerada fundamental para Roldão (1999), somente essa formação não garante a autonomia do professor, visto que se ficar somente no nível extrínseco não garante apropriação desses saberes diante de situações porque assim "[...] o conhecimento permanece como informação inerte e não se transforma num "saber em uso", corporizado em competências de acção e reflexão” (ROLDÃO, 1999, p. 84). 


\section{Considerações Finais}

Investigar, identificar e estudar o conteúdo das respostas e justificativas dos professores de Matemática quanto à contribuição dos materiais curriculares da Seesp em suas práticas docentes, possibilitou constatar seu significado de confirmação, negação ou o não reconhecimento de que a maioria pratica um entendimento parcial sobre essa contribuição.

Fica evidente que a não contribuição tem origem no próprio material da Seesp, precisamente no que se refere a sua forma de apresentação ou do conteúdo presente nele, considerado insuficiente. Várias justificativas para essas críticas negativas baseiam-se no fato de que é necessário fazer uma complementação para que seja possível utilizar o material. A partir disso, conclui-se que não se desenvolveu uma compreensão clara efetiva da proposta inicial, porque nela já estava prevista a complementação, pressupondo uma perspectiva não linear e flexível para o desenvolvimento de conteúdos, apoiada na autonomia do professor.

Esses resultados nos levam a refletir sobre a origem dos papéis assumidos pelos professores na relação professor - material curricular e sobre os saberes e competências docentes que concorrem nessa relação. Nesse sentido, a partir da defesa de Roldão (1999), sobreleva-se uma formação inicial e contínua no campo da gestão curricular. Além disso, clama-se a necessidade do desenvolvimento de saberes, competências e habilidades para essa gestão, nesse caso específico a partir de ações institucionalizadas da Seesp.

Nesse contexto, tomamos como referência o pressuposto curricular da própria Seesp "[...] ninguém é detentor absoluto do conhecimento e (que) o conhecimento coletivo é maior que a soma dos conhecimentos individuais, além de ser qualitativamente diferente" (SÃO PAULO, 2011, p. 11). Ele pode ser uma referência orientadora dessa formação e de estudos posteriores que possibilitem a sua efetividade. 


\section{Referências}

BARRETTO, E. S. de S. (Org.). Os currículos do Ensino Fundamental para as escolas brasileiras. Campinas: Autores Associados, 1998.

CANAVARRO, A. P.; PONTE, J. P. O papel do professor no currículo de matemática. In: Grupo de Trabalho de Investigação (Org.). O professor e o desenvolvimento curricular. Lisboa: Associação dos Professores de Matemática, 2005.

CERVO, A. L.; BERVIAN, P. A. Metodologia científica. 4. ed. São Paulo: Makron Books, 1996.

FERREIRA, M. S. O currículo e sua trama. In: ALMEIDA, M. D. de (Org.). Currículo como artefato social. 2. ed. Natal: EDUFRN, 2000. p. 17-30.

GOODSON, I. Currículo, narrativa e o futuro social. Revista Brasileira de Educação. v. 12. n. 35, p. 241-252, maio/ago. 2007.

LÜDKE, M.; ANDRÉ, M. E. D. A. de. A. Pesquisa em educação: abordagens qualitativas. São Paulo: EPU, 1986.

PACHECO, J. A. Globalização e identidades educativas: rupturas e incertezas. Revista Lusófona de Educação, v. 8, 2006, p. 13-28.

PIRES, C. M. C. Implementação de inovações curriculares em Matemática: embates com concepções, crenças e saberes de professores. In: MARANHÃO, C. (Org.). Educação matemática nos anos finais do Ensino Fundamental e Ensino Médio: pesquisas e perspectivas. São Paulo: Musa Editora, 2009. p. 167-190.

PIRES, C. M. C.; CURI, E. Desenvolvimento profissional de professores que ensinam matemática e materiais curriculares. VII CIBEM, 7., 2013, Montevideo. Actas... Montevideo, Uruguai, 2013a.

. Relações entre professores que ensinam matemática e prescrições curriculares.

Revista de Ensino de Ciências e Matemática, São Paulo, Unicsul, v. 4, n. 2, p. 57-74, 2013b.

REMILLARD, J. T.; HERBEL-EISENMANN, B. A.; LLOYD, G. M. Teachers' Use of Curriculum Materials: An Emerging Field. In: REMILLARD, J. T.; HERBEL-EISENMANN, B. A.; LLOYD, G. M. Mathematics Teachers at Work: Connecting Curriculum Materials and Classroom Instruction. 1. ed. Nova York: Routledge, 2009. p. 3-14.

REMILLARD, J. T. Examining Key Concepts in Research on Theachers' Use of Mathematics Curricula. Review of Educational Research, v. 75, n. 2, p. 211-246, 2005.

RIBEIRO, M. M. G. Diferentes espaços/tempos da organização curricular. In: ALMEIDA, M. D. (Org.). Currículo como artefato social. 2. ed. Natal, RN: EDUFRN, 2004, p. 11-16. 
RICO, L. ¿Qué debe investigar sobre los currículos de matemáticas? In: FÓRUM NACIONAL SOBRE CURRÍCULOS DE MATEMÁTICA, FNCM: Pesquisas e Políticas Públicas, 2., 2013, São Paulo. Anais... São Paulo: PUC-SP, 2013. p. 9-19.

ROLDÃO, M. C. Gestão curricular: fundamentos e práticas. Lisboa: Ministério da Educação, 1999.

SACRISTÁN, J. O currículo: uma reflexão sobre a prática. Porto Alegre: Artmed, 2008. SÃO PAUlO. Revista São Paulo Faz Escola - Edição especial da proposta curricular. Disciplina: Matemática - Ensino Fundamental Ciclo II. Coordenação Maria Inês Fini. São Paulo: FDE, 2008a.

. Proposta Curricular do Estado de São Paulo: Matemática. Coordenação. Maria Inês Fini. São Paulo: SEE, 2008b.

Secretaria da Educação. Currículo do Estado de São Paulo: Matemática e suas tecnologias. Coordenação geral Maria Inês Fini. Coordenação de área Nilson José Machado. 1. ed. atual. São Paulo: Secretaria da Educação, 2011. 